\title{
Tzanakis Score vs Alvarado Score in Acute Appendicitis
}

\author{
Sigdel GS, ${ }^{1}$ Lakhey PJ, ${ }^{2}$ Mishra PR ${ }^{2}$ \\ 'Department of Surgery, Kathmandu Model Hospital, Kathmandu, Nepal, ${ }^{2}$ Department of Surgery, Tribhuvan University \\ Teaching Hospital, Kathmandu, Nepal.
}

\section{ABSTRACT}

Introduction: Acute appendicitis is a common surgical emergency. Accurate diagnosis and timely intervention reduces mortality and morbidity. This study compared the efficacy of Tzanakis and Alvarado score in diagnosis of acute appendicitis.

Methods: A prospective, non randomized study was conducted in 100 consecutive patients who had undergone emergency appendectomy from May 2008 to October 2008. Tzanakis and Alvarado scores were obtained at the time of admission. Final diagnosis of acute appendicitis was based on histological findings.

Results: The sensitivity, specificity and overall diagnostic accuracy of Tzanakis score was $91.48 \%$ and $66.66 \%$ and $90 \%$ respectively. The sensitivity, specificity and overall diagnostic accuracy of Alvarado score was $81.91 \%$ and $66.66 \%$ and $81 \%$ respectively. Negative appendectomy rate was $6 \%$.

Conclusions: Tzanakis score is an effective modality to establish the accurate diagnosis of acute appendicitis.

\section{INTRODUCTION}

Acute appendicitis (AA) has a lifetime risk of $8.6 \%$ and $6.7 \%$ for men and women respectively. ${ }^{1-3}$ The accuracy of clinical examination in diagnosing $A A$ is $70 \%$ to $87 \% .{ }^{4,5}$ Approximately $20 \%$ to $33 \%$ of patients with suspected
AA have atypical findings making clinical diagnosis difficult. ${ }^{6,7}$ Diagnostic errors are common, resulting in median incidence of perforation of $20 \%$ and a negative laparotomy rate ranging from $2 \%$ to $30 \%$.

Correspondence:

Dr. Ghanshyam Sigdel

Department of Surgery

Kathmandu Model Hospital, Kathmandu, Nepal.

E-mail: sigdelgs@yahoo.com

Phone: 9841219013 
Alvarado score ${ }^{9}$ is widely used to diagnose $A A$; a score of 7 or more is considered diagnostic requiring surgery. ${ }^{9}$ Its sensitivity and specificity ranges from $73-90 \%$ and $87-92 \%$ respectively. ${ }^{10,11}$ Tzanakis score ${ }^{12}$ is a combination of clinical evaluation, ultrasonography and inflammatory markers. There are altogether four variables and 15 points and a score of 8 or more diagnoses AA requiring surgery. Its sensitivity, specificity and accuracy are $95.4 \%, 97.4 \%$ and $96.5 \%$ respectively. ${ }^{12 .}$ This study compares the efficacy of Tzanakis score with Alvarado score to diagnose AA.

\section{METHODS}

A prospective, non-randomized study was carried out in 100 consecutive patients with the clinical diagnosis of AA who underwent emergency appendectomy in Department of Surgery, Institute of Medicine (IOM) from May 2008 to October 2008. Informed consent was obtained from all participants. Ethical approval for the study was obtained from the institutional review board, IOM.

All patients with the clinical diagnosis of acute appendicitis underwent abdominal ultrasonography (USG), total and differential leukocyte count as part of their assessment. USG was done with a standard $5 \mathrm{MHz}$ linear transducer. The radiologist was blinded to the results of physical examinations and blood tests, but not to the patient's symptoms. Well established ultrasonographic criteria were applied to discriminate an acutely inflamed appendix from a normal one. ${ }^{13}$ Those with generalized peritonitis, appendicular abscess, appendicular lump, alternative diagnosis with normal appearing appendix detected during operation and those who did not consent for the study were excluded from the study.

Alvarado and Tzanakis score were obtained at the time of admission. Even when the scores were below the cut off value, patients were subjected for appendectomy based on clinical judgment. Final diagnosis of AA was based on histological findings.

Statistical analysis was done by using Statistical Package for the Social Sciences Software (SPSS) Program for windows ${ }^{\circledR}$ version 11.5. Fischer's exact test was used as a test of significance between categorical data. Diagnostic power of the two scoring systems was assessed by calculating the area under the receiveroperator characteristic (ROC) curve. Statistical significance was accepted at the 5 percent level.

\section{RESULTS}

Between May 2008 and October 2008, 107 patients with the clinical diagnosis of AA were assessed for eligibility; of these three refused to participate and four had an alternative diagnosis during operation (two salpingitis, one carcinoma caecum and one twisted right ovarian cyst). Finally a total of 100 patients underwent emergency appendectomy and were selected for this study. The most common position of the appendix was retrocecal $(81 \%)$. Ninety four percent had histologically proven AA. Negative appendectomy rate was $6 \%$ (female $4 \%$ and male $2 \%$ ). Negative appendectomy rate among female and male population was $14.2 \%$ and $2.77 \%$ respectively. The high negative appendectomy rate among female was not statistically significant $(P=0.05)$.

\section{Table 1. Demographic data}

\begin{tabular}{ll}
\hline Total no of patients & 100 \\
\hline Male : Female & $2.6: 1(72: 28)$ \\
Age in years* & $27.5 \pm 9.8(15-68)$ \\
Duration of symptoms (hours) $^{*} 25.4 \pm 19.5(3-96)$ \\
\hline$*$
\end{tabular}

* Mean \pm S.D (range)

AA was significantly high (Odd's ratio (OR) 21.5, confidence interval (Cl) 95\%, 3.40 to $136.13 ; \mathrm{P}=0.002$ ) in patients with Tzanakis score of 8 or more. The sensitivity and specificity of Tzanakis score in diagnosing AA was $91.48 \%$ and $66.66 \%$ respectively. The overall diagnostic accuracy was $90 \%$ with positive predictive value of $97.72 \%$ and negative predictive value of $33.33 \%$ (Table 2).

Table 2. Tzanakis score and histological diagnosis

\begin{tabular}{|c|c|c|c|}
\hline & Histological Dia & gnosis & \\
\hline Tzanakis score & Acute appendicitis & Normal appendix & Total patients \\
\hline 38 & 86 & 2 & 88 \\
\hline$<8$ & 8 & 4 & 12 \\
\hline Total patients & 94 & 6 & 100 \\
\hline
\end{tabular}

AA was significantly high (OR 9.06, Cl $95 \%, 1.53$ to 53.54; $P=0.017$ ) in patients with Alvarado score of 7 or more. The sensitivity and specificity of Alvarado score in diagnosing AA was $81.91 \%$ and $66.66 \%$ respectively. The overall diagnostic accuracy was $81 \%$ with positive predictive value of $97.46 \%$ and negative predictive value of $19.04 \%$ (Table 3 ).

Table 3. Alvarado score and histological diagnosis

\begin{tabular}{|c|c|c|c|}
\hline \multicolumn{4}{|c|}{ Histological Diagnosis } \\
\hline Tzanakis score & e Acute appendicitis & Normal appendix & Total patients \\
\hline 37 & 77 & 2 & 79 \\
\hline$<7$ & 17 & 4 & 21 \\
\hline Total patients & 94 & 6 & 100 \\
\hline
\end{tabular}


Table 4. Comparison of Tzanakis score in patients with Alvarado score of $<7$

\begin{tabular}{|c|c|c|c|}
\hline \multicolumn{4}{|c|}{ Histological Diagnosis } \\
\hline Tzanakis score & Acute appendicitis & Normal appendix & Total patients \\
\hline 38 & 12 & 1 & 13 \\
\hline$<8$ & 5 & 3 & 8 \\
\hline Total patients & 17 & 4 & 21 \\
\hline
\end{tabular}

When the Tzanakis score and the Alvarado score were analyzed for their efficacy in diagnosis of $A A$, the area under the ROC curve was 0.857 and 0.801 respectively $(\mathrm{P}=0.003$ and 0.014$)$ ( Figure 1).

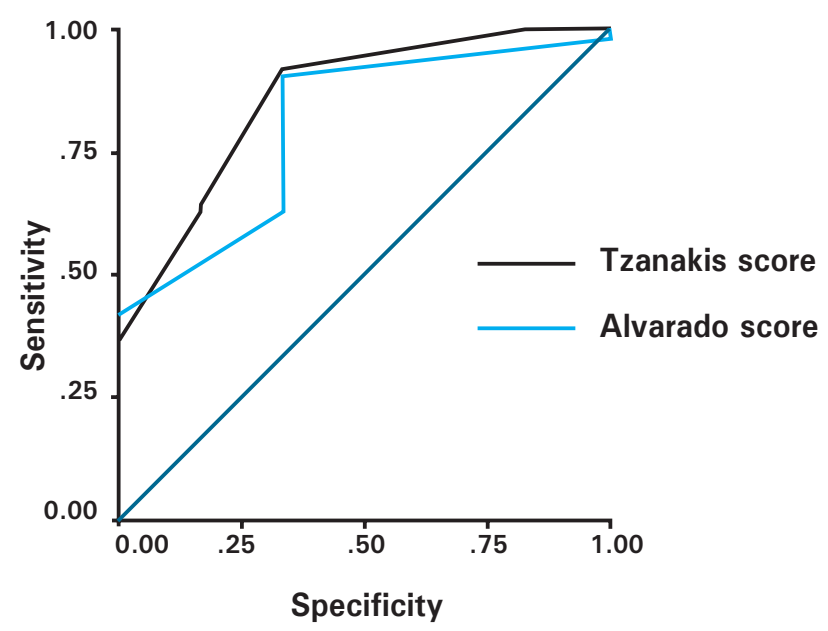

Figure 1. Receiver- operator characteristic (ROC) curve for the Tzanakis and Alvarado score in diagnosis of acute appendicitis

Among the 21 patients whose Alvarado score was below 7, 13 patients had Tzanakis score of 8 or more and 12 of them had histologically proven AA (Table 4). The sensitivity and specificity of Tzanakis score in this subset of patients was $70.58 \%$ and $75 \%$ respectively. However the ability to detect AA by Tzanakis score in patients with Alvarado score of less than 7 was not statistically significant $(P=0.133)$.

\section{DISCUSSION}

Diagnosis of AA is often a challenging job to the surgeon. Delayed diagnosis can lead to complications with high mortality and morbidity compared to non-perforated appendicitis. A high negative appendectomy rate of $15-$ $25 \%$ has been accepted in the past in the cost of preventing appendicular perforation. ${ }^{6,14}$ Negative appendectomy is not without complications. Though the mortality is low, it can be associated with morbidity of 10- $15 \% .{ }^{15}$ For these reasons negative appendectomy should be minimized by improving diagnostic accuracy. Diagnosis of AA is primarily based on surgeon's clinical impression. Besides clinical evaluation, various laboratory parameters of inflammation (leukocytosis and raised Creactive protein), radiological tools like ultrasonographic or computed tomographic evaluation of appendix and laparoscopy are used to establish an accurate diagnosis of acute appendicitis. These armamentarium has definitely increased the diagnostic accuracy and help to reduce negative appendectomy rate. However these techniques are not available universally.

Tzanakis et $\mathrm{al}^{12}$ have reported the sensitivity, specificity and accuracy of $95.4 \%, 97.4 \%$ and $96.5 \%$, respectively. The results of our study were comparable with that reported by Tzanakis et al. in terms of sensitivity, predicative value of positive test and overall diagnostic accuracy. The low specificity of Tzanakis score in this study was likely to be due to low sensitivity rate of USG $(63.82 \%)$ in detecting AA which was far below as compared to the literature $(85-96 \%) .^{5,9-12}$

Alvarado score has been validated in various studies with the sensitivity of $73-91 \%$ and specificity of $78-92 \% .^{9,11}$ The sensitivity of this score in the current study $(81.91 \%)$ was comparable with the other reports. However, the specificity of Alvarado score in this study (66.66\%) was quite low compared to other studies. Low specificity of Alvarado score was explained by the high rate of false positive $(33.3 \%)$ result.

The current study aimed to compare the efficacy of Tzanakis score with the Alvarado score in the diagnosis of AA. Tzanakis score was superior in terms of its sensitivity, diagnostic accuracy and predictive value of negative test. The false negative rate of Alvarado score in the diagnosis of AA was $18.08 \%$, whereas that of Tzanakis score was only $8.51 \%$. Both the scoring systems yielded an equal and a low specificity rate of $66.66 \%$.

This study has shown a negative appendectomy rate of $6 \%$. Majority of our patients presented late (mean duration of symptoms 25.4 hours), which increases the rate of positive clinical findings as well as laboratory parameters for AA. This has probably led to a more accurate preoperative diagnosis and hence the lower rate of negative appendectomy in our setup. This study had some limitations. Both clinical and ultrasonographic evaluations were done by different persons, allowing place for inter-observer differences in findings.

\section{CONCLUSIONS}

In conclusion, a good clinical judgment aided by investigations and scoring system can help to reduce the 
negative appendectomy rate. Tzanakis scoring system can be used as an effective modality to establish the accurate diagnosis of acute appendicitis with reasonably low negative appendectomy rate.

\section{REFERENCES}

1 Flum DR, Koepsell T. The clinical and economic correlates of misdiagnosed appendicitis. Arch Surg. 2002;37:799-804.

2 Rothrock SG, Pagane J. Acute appendicitis in children: emergency department diagnosis and management. Ann Emerg Med. 2000;6:39-51.

3 Shelton T, McKinlay R, Schwartz RW. Acute appendicitis: current diagnosis and treatment. Curr Surg. 2003;60:502-5.

4 John H, Neff U, Kelemen M. Appendicitis diagnosis today: clinical and ultrasonic deductions. World J Surg. 1993;17:243-9.

5 Saidi RF, Ghasemi M. Role of Alvarado score in diagnosis and treatment of suspected acute appendicitis. Am J Emerg Med. 2000;18:230-1.

6 Lewis FR, Holcroft JW, Boey J, Dunphy JE. Appendicitis: A critical review of diagnosis and treatment in 1000 cases. Arch Surg. 1975;110:677- 84 .

7 Berry J Jr, Malt RA. Appendicitis near its centenary. Ann Surg 1984;200:567-75.

8 Andersson RE. Meta-analysis of the clinical and laboratory diagnosis of appendicitis. Br J Surg. 2004;91:28-37.
9 Fenyo G, lindenberg G, Blind P, Enchsson L, Oberg A. Diagnostic decision support in suspected acute appendicitis: validation of a simplified scoring system. Eur J Surg. 1997;163(11):831-8.

10 Fenyo G. Routine use of a scoring system for decision-making in suspected acute appendicitis in adults. Acta Chir Scand. 1987;153:545-1.

11 Cox MR, Mc Call JL, Padbury RT, Wilson TG, Wattchow DA, Toouli J. Laparoscopic surgery in women with a clinical diagnosis of acute appendicitis. Med J Aust. 1995;162:130.

12 Tzanakis NE, Efstathiou SP, Danulidis K, Rallis GE, Tsioulos DI, Chatzivasiliou A, Peros G, Nikiteas NI. A New Approach to Accurate Diagnosis of Acute Appendicitis. World J Surg. 2005;29:1151-6.

13 Townsend CM, Beauchamp DR, Evers BM, Mattos KL. Sabiston Text book of Surgery. 17th ed. Philadelphia:Saunders; 2004. p. 1381-99.

14 Humes DJ, Simpson J. Acute appendicitis. BMJ. 2006;333(7567):530-4.

15 Raf LE. Causes of abdominal adhesions in cases of intestinal obstruction. Acta Chir Scand. 1969;135:73-6. 